\title{
Effects of fire retardants on jute fiber reinforced polyvinyl chloride/polypropylene hybrid composites
}

\author{
Shovon Bhattacharjee ${ }^{1, ~ *, ~ M u h a m m a d ~ H a s n a n ~ S a z z a d ~}{ }^{1}$, Muhammed Ariful Islam, \\ M. M. Ahtashom ${ }^{1}$, Asaduzzaman ${ }^{2}$, Muhammed Yusuf Miah ${ }^{1}$ \\ ${ }^{1}$ Department of Applied Chemistry and Chemical Engineering, Noakhali Science and Technology University, Noakhali, Bangladesh \\ ${ }^{2}$ Scientific Officer, IFST, Bangladesh Council of Scientific and Industrial Research, Dhaka, Bangladesh
}

\section{Email address:}

shovon_nstu@yahoo.com (S. Bhattacharjee), engsazzad23@yahoo.com (M. H. Sazzad), cmiarief@gmail.com (M. A. Islam), evan.ctg@gmail.com (M. M. Ahtashom), asad.acce@gmail.com (Asaduzzaman), yuri19742003@yahoo.com (M.Y. Miah)

\section{To cite this article:}

Shovon Bhattacharjee, Muhammad Hasnan Sazzad, Muhammed Ariful Islam, M. M. Ahtashom, Asaduzzaman, Muhammed Yusuf Miah. Effects of Fire Retardants on Jute Fiber Reinforced Polyvinyl Chloride/Polypropylene Hybrid Composites. International Journal of Materials Science and Applications. Vol. 2, No. 5, 2013, pp. 162-167. doi: 10.11648/j.ijmsa.20130205.13

\begin{abstract}
Jute fiber (50 \%) reinforced PVC+PP hybrid composites were prepared by injection molding and heat pressing. Mechanical properties (tensile strength, TS; bending strength, BS; tensile modulus, TM; bending modulus, BM; and impact strength, IS) and burning speed of composites were studied. Hybrid composite of $55 \%$ PP and $45 \%$ PVC showed the best results and was selected as desired specimen. TS, BS, TM, BM, IS and burning speed of the selected desired specimen (SDS) was found as $63.6 \mathrm{MPa}, 68.7 \mathrm{MPa}, 1.38 \mathrm{GPa}, 1.76 \mathrm{GPa}, 24 \mathrm{KJ} / \mathrm{m}^{2}$ and $3.2 \mathrm{~cm} / \mathrm{min}$ respectively. Finer particle size Aluminium trihydrate (ATH) and Zinc borate with Antimony Trioxide (ZB-AT) was used as fire retardants. TS and IS decreased; on the contrary, TM and BM increased with increasing both AT and ZB-AT. But BS decreased with increasing ATH and increased with increasing ZB-AT. Burning speed of SDS reduced to $2.8 \mathrm{~cm} / \mathrm{min}$ and $2.2 \mathrm{~cm} / \mathrm{min}$ after using $10 \%$ ATH and $10 \%$ ZB-AT (ZB, 7.5\%; AT, 2.5\%) respectively.
\end{abstract}

Keywords: Fire Retardants, Flammability, Jute Fiber, PVC-PP Composite, Hybrid Composite Material, Zinc Borate, Aluminium Trihydrate, Mechanical Properties, Statistical Analysis

\section{Introduction}

Nowadays, due to environmental awareness and economic considerations; the natural fiber reinforced composite materials have been the subject of several studies to provide a possible replacement material to synthetic fiber (such as glass, aramid and carbon fibers) reinforced polymer composites [1]. Natural fiber reinforced (NFR) composites are environment friendly, renewable, recyclable, less abrasive, light-weight and economically sound. The NFR composites can be used in wide range of applications because of their better performance, higher ultimate strain and good impact resistance. The main advantages of natural fibers are availability, biodegradability and $\mathrm{CO}_{2}$ neutrality when they are incinerated $[2,3]$.

Among all the natural fibers, jute appears to be the most useful, inexpensive and commercially available fiber. Jute can be molded into a variety of flat and complex-shaped components by exploiting their attractive reinforcing potential. In addition, the jute is one of the best fibers in terms of resistance, mechanical properties, flexibility. It can be combined with different polymer resins at lower processing temperature [4]. But the reality is that when synthetic fibers came onto the market, most people accepted them because of their mechanical strength and high durability. Now scientists are trying to encourage use of this fiber for its excellent biodegradability, low cost, and good mechanical properties [5].

Thermoplastic resin based composites are popular due to their processing advantages and satisfactory mechanical properties [6]. Among commodity thermoplastics, Polypropylene (PP) and Polyvinyl chloride (PVC) possesses some outstanding properties.

PP is a semi-crystalline thermoplastic linear structured polymer. PP is widely used as a matrix material because it has some excellent characters for composite fabrication. It possesses several vital and useful properties as good resistance to fatigue, melting point of $170{ }^{\circ} \mathrm{C}$, transparency, dimensional stability, flame resistance, high heat distortion 
temperature, and high impact strength, low density, good flex life, good surface hardness, scratch resistance, very good abrasion resistance, and excellent electrical properties $[4,5,7]$. PP can be used extensively for manufacturing automotive components, home appliances and other industrial products because of its balanced mechanical properties, good process ability and low-cost [8].

$\mathrm{PVC}$ is linear structured and non-polar thermoplastic polymer having density of $1.34 \mathrm{~g} / \mathrm{cm}^{3}$. PVC's intrinsic properties have made it suitable for a wide range of applications. It is stronger and stiffer than polypropylene. One of principal beneficial properties of PVC is that it is inherently flame resistant which contains about $57 \%$ chlorine. PVC is the third most widely used thermoplastic polymer. It is cheap, durable and easy to assemble as a building material. Over $50 \%$ of PVC manufactured is used around the world in construction. It has high level of resistance to dilute and concentrated acids, alcohols, bases, aliphatic, mineral oils and oxidizing agents. It is a very popular material and has many uses within industry and fabrication applications. Again, PP and PVC composites show a good combination of mechanical property, chemical stability, water resistance and cost index. In recent years, natural fiber reinforced PP / PVC composites are finding increasing applications in engineering items such as bodies of electronic appliances, transport vehicle, building materials and automotive industry and many more [9-12].

Jute Fiber Reinforced Polyvinyl Chloride (PVC) / Polypropylene (PP) Hybrid Composites show strong mechanical properties. Although they can be used in a wide range of applications, a major threat and drawback of Jute fiber reinforced Polyvinyl Chloride (PVC) / Polypropylene (PP) hybrid composites is their high flammability. Flammability is defined as how easily something will burn or ignite, causing fire or combustion. As organic materials, the polymer and the fibers are very sensitive to flame; improvement of flame retardant property of the composite materials has become more and more important in order to comply with the safety requirements of the composite products [13]. Fire retardants are incorporated chemically or blended physically into the composites to achieve a desired fire resistivity. In this work Aluminium trihydrate and Zinc borate with Antimony trioxide co-additive has been used as fire retardants. Different amount of fire retardants are added in different proportion in the polymer composite. The effect of these fire retarding agents on the mechanical properties and flammability of jute fiber reinforced PP/PVC hybrid composite has also been evaluated.

The main attention in this study is drawn to prepare the fire retardant jute fiber reinforced Polyvinyl Chloride (PVC)/Polypropylene (PP) hybrid composites using suitable fire retarding agents, assessment of mechanical properties (such as: Tensile strength, Bending strength, Tensile modulus, Bending modulus and Impact strength) and flammability of the composites after the addition of fire retardants.

\section{Experimental Methods}

\subsection{Materials}

Hessian cloth (unbleached, Tossa Jute), Polyvinyl chloride and polypropylene (injection molding grade), Fire retardants i.e. Aluminium trihydrate (median particle size; 1 micro meter), Antimony trioxide and Zn-borate (median particle size; 2 micrometer)

\subsection{Composites Fabrication}

\subsubsection{Jute Fiber Reinforced PVC/PP Hybrid Composite}

The PVC and PP test specimens were injection molded separately by using injection-molding machine with a barrel temperature of $185-190{ }^{\circ} \mathrm{C}$. All test specimens were conditioned under ambient condition for at least $48 \mathrm{hrs}$ prior to testing. The jute fiber was dried in oven at $105^{\circ} \mathrm{C}$ for 2 hours. The sheets and jute fibers were cut into desired size for composite fabrication and weighed. Composites were prepared by sandwiching 4 layers of jute fabrics (50\%) between 5 layers of polymer matrix of varying proportion (PP, PVC and mixture of PP \& PVC) and pressed at $200{ }^{\circ} \mathrm{C}$ for 5 minutes between two steel plates under a pressure of 5 tons with the use of heat press. Afterwards using another press (Carver, USA) composite containing steel sheets was cooled to room temperature and then cut to the desired size with the use of cold press.

\subsubsection{Fire Retardants Incorporated Jute Fiber Reinforced PVC/PP Hybrid Composite}

Fire retardants and polymers were compounded by simultaneous addition to counter-rotating screw extruder with a barrel temperature of $185^{\circ} \mathrm{C}$ and a rotor speed of 15 $\mathrm{rpm}$ in order to determine the optimum blend formulation of polymer and fire retardants. The preparation of composite specimens from the extruded materials was carried out using the same machines and conditions mentioned above.

\subsection{Mechanical Properties and Fire Retardant Test of the Composites}

Tensile strength (TS), bending strength (BS), tensile modulus (TM) and bending modulus (BM) of the composites were determined by a universal testing machine according to DIN 53455 and DIN 53452 standard methods. The impact strength (IS) was measured according to DIN EN IS0179 standard in the flat wise by using impact tester. The fire retardant test was carried out using UL 94 standard. All the results were taken as the average values of 10 samples.

\section{Results and Discussion}

\subsection{Relative Studies of the Mechanical and Burning Properties of the Pure Polymers}

At first of the experiment, the mechanical and burning 
properties of the pure PVC and PP polymers were assessed

Table 1. Mechanical and burning characteristics of the used polymers

\begin{tabular}{lll}
\hline Property & PVC Sheet & PP Sheet \\
\hline Tensile Strength & $39.2 \mathrm{MPa}$ & $30.1 \mathrm{MPa}$ \\
Tensile Modulus & $0.95 \mathrm{GPa}$ & $0.69 \mathrm{GPa}$ \\
Bending Strength & $43.2 \mathrm{MPa}$ & $38.3 \mathrm{MPa}$ \\
Bending Modulus & $1.02 \mathrm{GPa}$ & $0.93 \mathrm{GPa}$ \\
Impact Strength & $15 \mathrm{KJ} / \mathrm{m}^{2}$ & $13 \mathrm{KJ} / \mathrm{m}^{2}$ \\
Burning Speed & $2.9 \mathrm{~cm} / \mathrm{min}$ & $3.4 \mathrm{~cm} / \mathrm{min}$ \\
\hline
\end{tabular}

which are presented in Table 1. The sole objective of this work was to improve these properties by combining PVC and $\mathrm{PP}$, and reinforcing with jute fiber which were handled in the following steps.

\subsection{Comparative Studies of the Mechanical Properties of Jute Fiber Reinforced PVC/PP Hybrid Composites}

The mechanical properties such as tensile strength (TS), bending strength (BS), tensile modulus (TM), bending modulus (BM), impact strength (IS) of the mixture of PP and PVC matrices based hybrid composites were evaluated and the values are displayed in Table 2. The jute fiber content in the composites was maintained about $50 \%$ by weight. The effect of combination of PP content with PVC on the tensile and bending strength of the composites showed that TS and BS values were increased gradually with the increase of PP content in PVC up to $55 \%$ and with further addition of PP in PVC, the values were gradually decreased. Mixture of PP and PVC matrix based composite containing $55 \% \mathrm{PP}$ and $45 \%$ PVC performed the best results and reported that the TS and BS of 63.6 and 68.7 $\mathrm{MPa}$ respectively. Tensile strength were found to be 53.7 , 60.9 and $60.1 \mathrm{MPa}$ for jute/(25\% PP + $75 \% \mathrm{PVC})$, jute/(45 \% PP + $55 \%$ PVC) and jute/(75\% PP + $25 \%$ PVC) composites respectively while BS values were found to be 59.3, 66.1 and $64.1 \mathrm{MPa}$ respectively. Polymer matrix composite made of $55 \%$ PP $+45 \%$ PVC reinforced with jute showed higher TS and BS than that of the other mixed composites. The reason behind the increase of TS and BS for this mixed composite may be explained on the basis of viscosity. During composite fabrication at higher $\left(200{ }^{\circ} \mathrm{C}\right)$ temperature, the high viscous PP impregnated into the fiber and PVC which caused better bonding. Though PP has lower TS and BS, several (55) percentage of PP into the PVC can improve the TS and BS and thus indicates synergistic effect in the composites [4]. Actually, PP has melting point of about $170{ }^{\circ} \mathrm{C}$ but PVC has $155{ }^{\circ} \mathrm{C}$. The composites were fabricated at $200{ }^{\circ} \mathrm{C}$. At higher temperature, PP became too much viscous and properly mixed with the jute and PVC. As a result, the composites containing $55 \% \mathrm{PP}+45 \%$ PVC performed the best results.

Table 2. Mechanical properties of jute fiber (50 wt. \%) reinforced polyvinyl chloride / polypropylene hybrid composites

\begin{tabular}{ccccccc}
\hline PVC (\%) & PP (\%) & $\begin{array}{c}\text { Tensile Strength } \\
(\mathbf{M P a})\end{array}$ & $\begin{array}{c}\text { Tensile Modulus } \\
(\mathbf{G P a})\end{array}$ & $\begin{array}{c}\text { Bending Strength } \\
(\mathbf{M P a})\end{array}$ & $\begin{array}{c}\text { Bending Modulus } \\
(\mathbf{G P a})\end{array}$ & $\begin{array}{c}\text { Impact Strength } \\
\left(\mathbf{K J} / \mathbf{m}^{2}\right)\end{array}$ \\
\hline 75 & 25 & 53.7 & 1.1 & 59.3 & 1.42 & 22 \\
55 & 45 & 60.9 & 1.3 & 66.1 & 1.68 & 23 \\
45 & 55 & 63.6 & 1.38 & 68.7 & 1.76 & 24 \\
25 & 75 & 60.1 & 1.23 & 64.1 & 1.61 & 22 \\
\hline
\end{tabular}

All the results were taken as the mean values of 10 samples

In contrast, both tensile and bending modulus exhibited continuously increasing trends from $25 \%$ to $55 \% \mathrm{PP}$ content in PVC matrix as like as TS and BS and further increasing of PP content decreased the values. Polymer matrix containing $55 \%$ PP showed higher TM and BM than that of the other mixed composites and the values were found to be $1.38 \mathrm{GPa}$ and $1.76 \mathrm{GPa}$ respectively. Tensile modulus were found to be $1.1,1.3$ and $1.23 \mathrm{GPa}$ for jute/(25\% PP + $75 \%$ PVC $)$, jute/(45 \% PP + $55 \%$ PVC $)$ and jute/(75\% PP $+25 \%$ PVC) composites respectively while $\mathrm{BM}$ values were found to be $1.42,1.68$ and $1.61 \mathrm{GPa}$ respectively. The reason behind the decrease of mechanical properties above $55 \% \mathrm{PP}$ content in polymer matrix is due to the high melt flow rate of PP.

Moreover, from the Table 2, it is observed that the jute/(55\% PP + $45 \%$ PVC) composite showed the highest impact strength and the value was found to be $24 \mathrm{~kJ} / \mathrm{m}^{2}$.

From this study, it is clear that jute fabrics reinforced $55 \%$ PP + $45 \%$ PVC composite possessed sufficiently higher values of TS, TM, BS, BM and IS compared to that of the other mixed polymer matrix composites. Therefore, this particular composite was further used as selected desired specimen (SDS) composite in the following steps with different fire retardants for observing their consequences on different properties. 


\subsection{Effects of the Incorporation of Fire Retardants on the Mechanical Properties of the Selected Desired Specimen (SDS) Composite}

Mechanical properties of the prepared jute fiber reinforced PVC/PP hybrid composites with different proportion of fire retardants were measured in terms of TS, TM, BS, BM and IS. Aluminium trihydrate (ATH) and Zinc borate with Antimony Trioxide (ZB-AT) were used in this phase as potential fire retardants. Addition of Antimony trioxide to Zinc borate improves the layer durability and structure. The mixing ratio of ZB and AT was maintained $3: 1$ as it was recognized as the optimum mixing ratio for obtaining the best result [14].

\subsubsection{Tensile Behavior}

The results for the tensile behaviors for different blends of ATH/SDS and ZB-AT/SDS composites are plotted in Fig. 1 and 2 respectively.

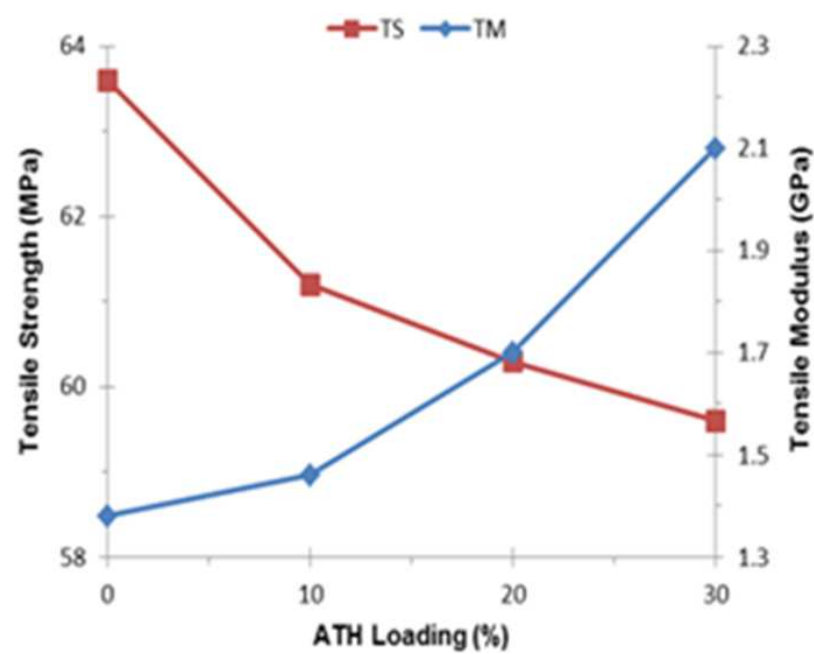

Figure 1. Effect of ATH loading on tensile strength and tensile modulus of ATH/SDS blend

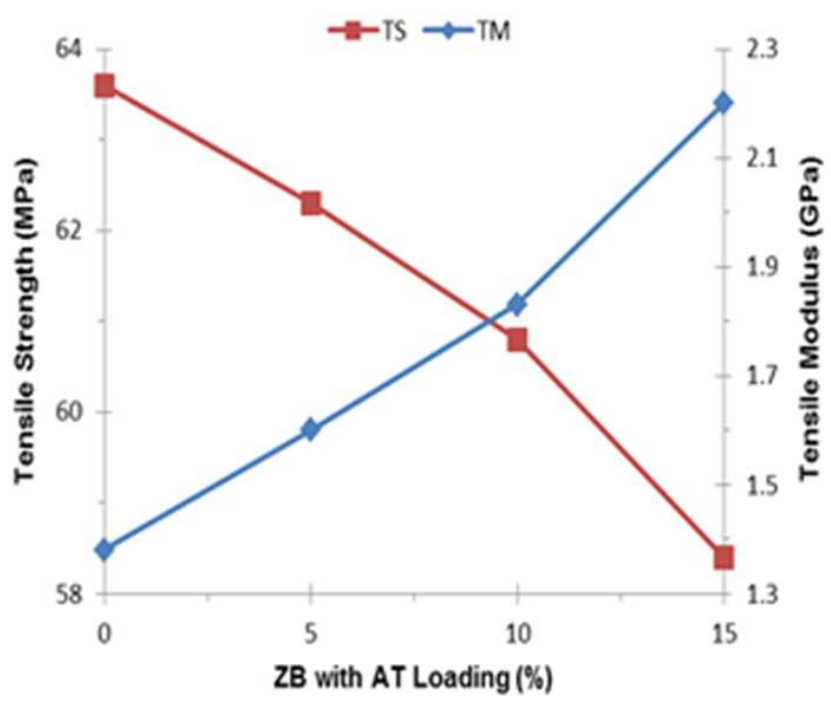

Figure 2. Effect of ZB-AT loading on tensile strength and tensile modulus of $Z B-A T / S D S$ blend
It was observed that tensile strength of the composite decreased with the increasing amount of ATH and ZB-AT individually in the blend. SDS composite is stronger than both the ATH/SDS and ZB-AT/SDS composites. This decrease in the strength was because of the week intermolecular forces between SDS composite and flame retardants. On the other hand, tensile modulus is seen to increase sharply with the addition of more ATH and ZB-AT separately in the composite. It can be realized that SDS composite has the maximum tensile strength (63.6 MPa) while $15 \%$ ZB-AT mixed with SDS composite has the maximum tensile modulus (2.2 GPa).

\subsubsection{Bending Behavior}

Fig. 3 and 4 respectively show the effects for the bending performances for different blends of ATH/SDS and ZB-AT/SDS composites.

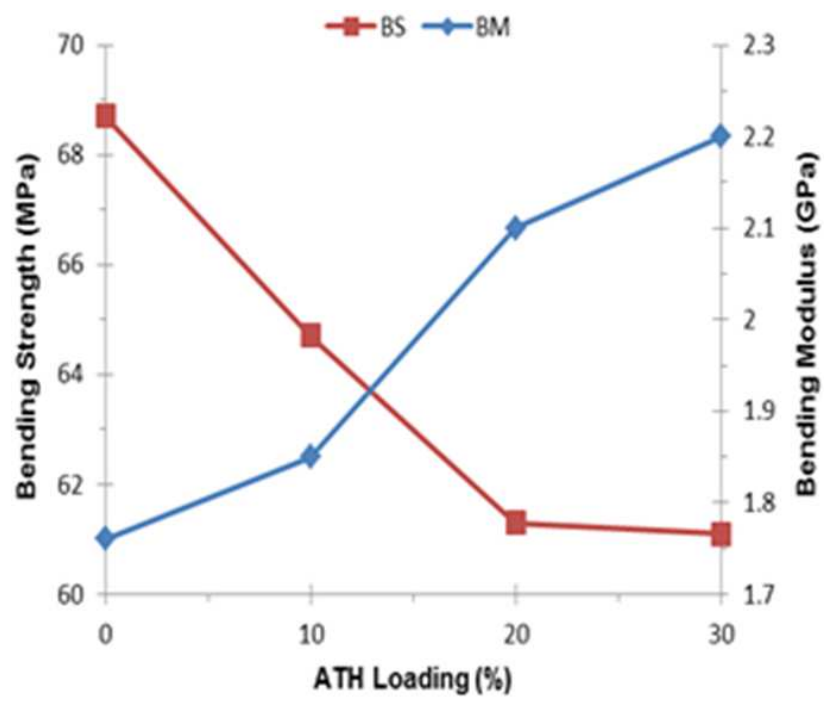

Figure 3. Effect of ATH loading on bending strength and bending modulus of ATH/SDS blend

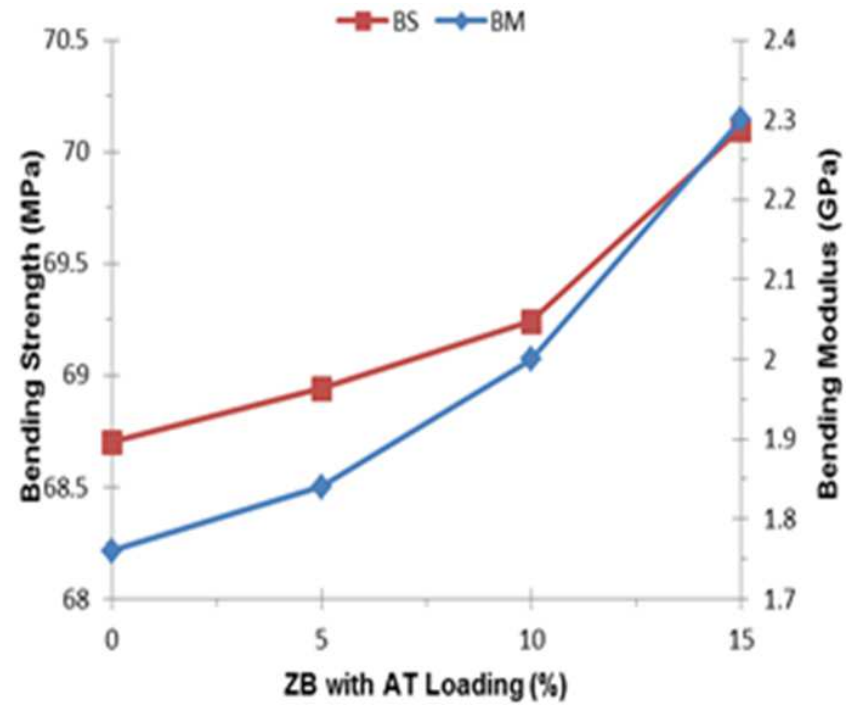

Figure 4. Effect of ZB-AT loading on bending strength and bending modulus of $Z B-A T / S D S$ blend 
It was observed that bending strength of the composite is decreasing with the increasing amount of ATH in the blend while the replacement of ATH by ZB-AT gives rise to a maximum increase up to $70.1 \mathrm{MPa}$ for $15 \%$ loading in the bending strength of the composite. This might be explained in that the intermolecular force is broken easily in the composites which have higher amount of ATH. On the contrary, bending modulus is seen to increase significantly with the addition of more ATH and ZB-AT individually in the composite. It can be seen that the blend having $15 \%$ ZB-AT has the highest bending modulus $(2.3 \mathrm{GPa})$ while blend having $30 \%$ ATH has the lowest bending strength (61.1 MPa).

\subsubsection{Impact Strength}

The effects for the impact strength for different blends of ATH/SDS and ZB-AT/SDS composites are schemed and illustrated in Fig. 5 and 6 respectively. The impact strength was remarkably reduced by the addition of ATH in the composite and showed maximum decrease of $38 \%$ for $30 \%$ ATH loading. In contrast, ZB-AT/SDS composite showed a slight reduction in the impact strength with the increasing amount of ZB-AT fire retardant in the composite. It can be seen that both the fire retardants create poor impact strength of the SDS composite.

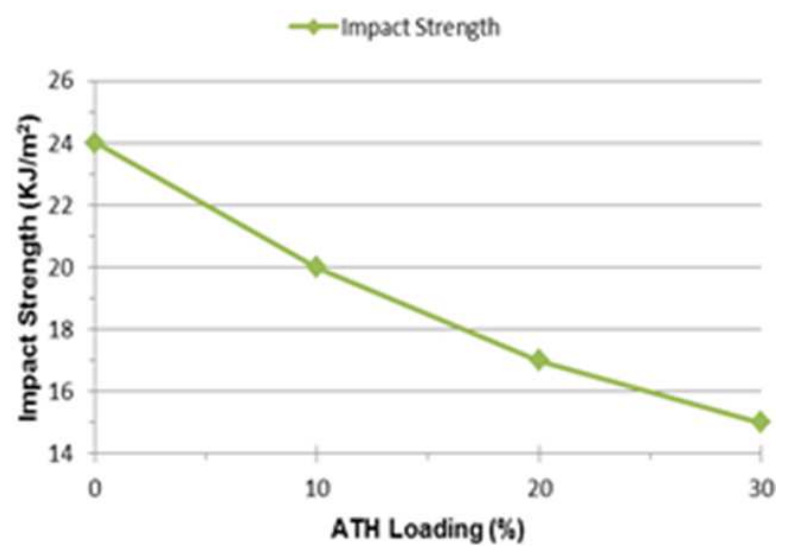

Figure 5. Effect of ATH loading on impact strength of ATH/SDS blend

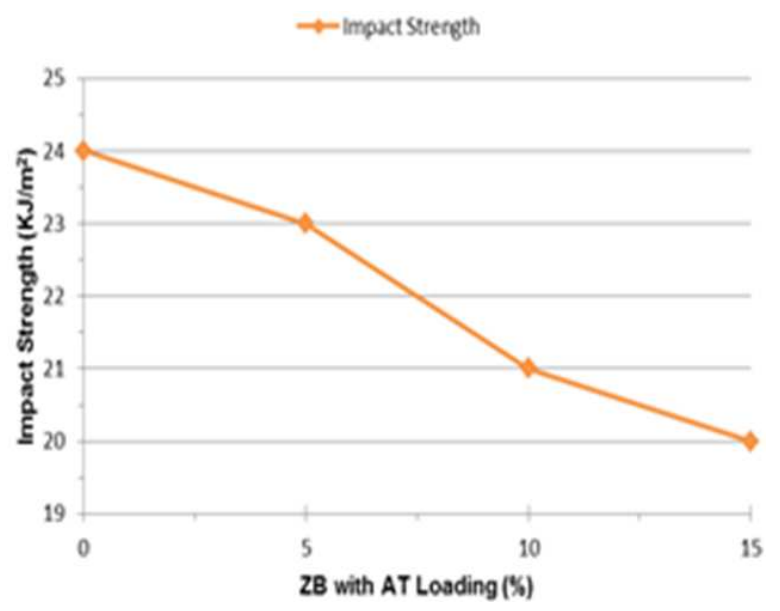

Figure 6. Effect of $Z B$-AT loading on impact strength of $Z B-A T / S D S$ blend

\subsection{Fire Retardant Properties}

The role of fire retardants on the burning performance (burning speed) of the composites were studied. The burning speed of the composites with and without fire retardants is shown in Fig. 7. SDS composite was highly combustible having burning speed of $3.2 \mathrm{~cm} / \mathrm{min}$. However, the incorporation of fire retardants had a progressive influence on the SDS composite. When ATH and ZB-AT were incorporated individually with SDS composite, its flame retardant properties were greatly improved. It was observed from the figure that $10 \%$ ATH incorporation showed a moderate burning speed of $2.8 \mathrm{~cm} / \mathrm{min}$ while $10 \%$ ZB-AT exhibited an incredible progress in the fire retardancy having burning speed of about $2.2 \mathrm{~cm} / \mathrm{min}$. ATH degrade endothermally and cools down the substrate to a temperature below that requires for sustaining the combustion process. Again ZB form a glassy inorganic layer and increase char formation and boost fire retardant property [15-17].

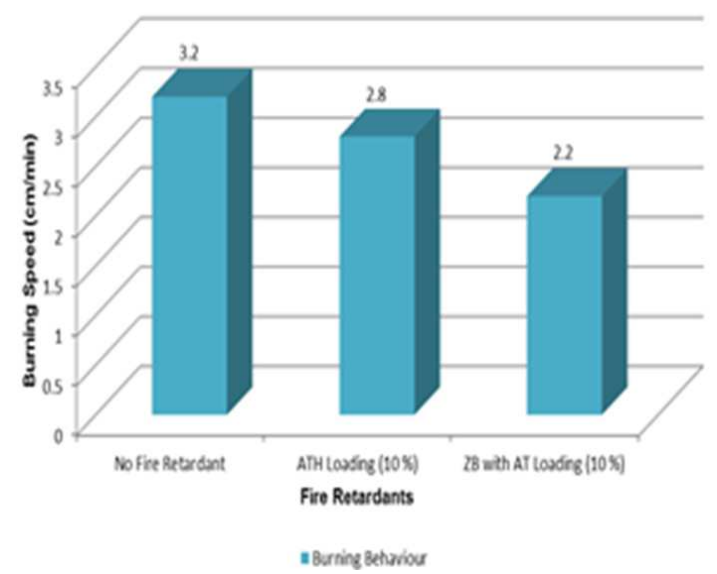

Figure 7. Burning speed (cm/min) of SDS composite with and without fire retardants

\section{Conclusions}

The overall result highlights the effects of the composition and new information to assist the improvement of fire retardancy performance of composite materials, offering technology toward another effective environmental safeguarding. The attempt was conducted to fabricate the jute fiber/PVC-PP composite and to investigate the effects of using $\mathrm{ATH}$ and $\mathrm{ZB}$ as fire retardant materials on the mechanical behavior of the optimum composite, with a recommendation for their use. It was observed that the inclusion of ATH and ZB-AT in the composite influenced mechanical properties as a result of their less compatibility with fibers or PP or PVC. Therefore, tensile strength and impact strength of the composite decreased with the increase in the wt. \% of ATH and ZB-AT loading in the blend separately with a concomitant increase in the bending modulus and tensile modulus. Bending strength decreased by increasing the ATH content while enhanced with the incorporation of ZB-AT. The new compounds are expected 
to have improved fire resistance performance over the virgin matrix but the most important aspect is that the enhancement of fire retardancy is sometimes on the expense of the mechanical strength of the composite laminates. In this context, this work suggests that the improvement of fire retardancy of composite without any loss of mechanical characteristics can be achieved by using chemically reactive fire retardants at low concentrations. Still much work is to be done on the flammability of the composite to fully characterize and optimize their effects and to ensure their successful application as well as to establish their commercial viability.

\section{References}

[1] T. D. Hapuarachchi, G. Ren, M.Fan, P. J. Hogg and T. Peijs, "Fire retardency of natural fibre reinforced sheet moulding compound,"Appl Compos Mater, vol. 14, pp. 251-264, 2007.

[2] A. K. Bledzki and J. Gassam, "Composites reinforced with cellulose based fibers," Prog. Poly. m. sci., vol. 24, pp. 221-274, 1999.

[3] P. Wambua, J. Ivan and I. Verport, "Natural fibres: can they replace glass in fibre reinforced plastics," Compos. Science Technol., vol. 63, pp. 1259-1264, 2003.

[4] H.U. Zaman, A. H. Khan, M. A. Hossain, M. A. Khan and R. A. Khan, "Mechanical and electrical properties of jute fabrics rainforced polyethylene/polypropylene composites: role of Gamma radiation,’Polym. Plast. Technol. Eng., vol. 48, pp. 760-766, 2009.

[5] M. A. Khan, R.A. Khan, Haydaruzzaman, A. Hossain and A. H. Khan, "Effect of Gamma radiation on the physic-mechanical and electrical properties of jute fiber reignforced polypropylene composites," Journal of Reign. Plast. And comp, vol. 28, no.13, 2009.

[6] A. K. Rana, A. Mandal, B. C. Mitra, R. Jacobson, R. Rowell and A. N. Banerjee, "Short jute fiber-reinforced polypropylene composites: effect of compatibilizer," Journal of Applied Polymer Science, vol. 69, pp. 329-338, 1998.

[7] M. A. Khan, G. Hinrichsen and L. T. Drzal, "Influence of novel coupling agents on mechanical properties of jute-reinforced polypropylene composite," J. Mater. Sci. Lett., vol. 20, pp. 1711-1713, 2001.

[8] M. F. Mina, S. Seema, R. Matin, M. J. Rahaman, R. B. Sarker, M. A. Gafur and M. A. H. Bhuiyan, "Improved performance of isotactic polypropylene/titanium dioxide composites: Effect of processing conditions and filler content," Polym. Degrad. Stab., vol. 94, no. 2, pp. 183-188, 2009.

[9] A. A. Klyosov, Wood-plastic composites. Hoboken, New Jersey: John Wiley \& Sons, Inc., 2007, pp. 56-60.

[10] S. Sun, C. Li, L. Zhang and H. L. Du, "Interfacial structure and mechanical properties of PVC composites reinforced by $\mathrm{CaCO}_{3}$ with different particle size and surface treatment," Polym. Int., vol. 55, pp. 158-164, 2006.

[11] A. K. Bledzki and J. Gassan, "Composites reinforced with cellulose based fibres," Prog. Polym. Sci., vol. 24, pp. 221-274, 1999.

[12] C. H. Chen, C. H. Li, C. C. Teng and C. H. Yang, "Fusion, electrical conductivity, thermal and mechanical properties of rigid poly (vinyl chloride) (PVC)/carbon black (CB) composites," Journal of Applied Polymer Science, vol. 99, pp. 2167-2173, 2006.

[13] J. K. Kim and K. Pal, "Recent advance in the processing of wood plastic composites," Engineering Materials, vol. 32, 2011.

[14] M. Al-Maamori, A. Al-Mosawi and A. Hashim, "Flame retardancy enhancement of hybrid composite material by using inorganic retardants," Materials Sciences and Application, vol. 2, pp. 1134-1138, 2011.

[15] S. Bourbigot and S. Duquesne, "Fire retardant polymers: recent developments and opportunities," Journal of Materials Chemistry, April, 2007.

[16] M. T. Albdiry, A. I. Almosawi and B. F. Yousif, "The synergistic effect of hybrid flame retardants on pyrolysis behaviour of hybrid composite materials", Journal of Engineering Science and Technology, vol. 7(3), pp. 351-359, 2012.

[17] A. R. Shah, D. Lee, S. Kim, A. Wasy, Y. Q Wang, K. C. Ham, K. Jayaraman, B. S. Kim and J. I Song, "Effect of wt \% of ATH on mechanical strength of Polypropylene/Aluminium Trihydrate (PP/ATH) composite," 9th International Conference on Fracture \& Strength of Solids, June 2013. 